\title{
Anionic Polymerization of Methyl Methacrylate by Alkali Metal Alkoxide
}

\author{
Masao Tomor, Keiichi Sekiya, and Hiroshi KaKIUchI \\ Department of Applied Chemistry, Faculty of Engineering, \\ Yokohama National University, Yokohama, Japan.
}

(Received April 1, 1974)

\begin{abstract}
The polymerization of methyl methacrylate by alkali metal alkoxides was carried out in aprotic dipolar solvents such as hexamethylphosphoramide, dimethylsulfoxide, and dimethylacetamide. The polymerization was drastically promoted by these solvents, even by the presence of small quantities of them. Tetramethylethylenediamine and ethereal solvents also promoted the reaction, although these solvents were less effective than the aprotic dipolar type. Such an effect of the solvent was explained in terms of the donor property and the dielectric constant of the solvent. Alkali metal salts of 2-substituted ethanols such as 2-methoxyethanol and 2-dimethylaminoethanol were effective as the initiator. The structure of the polymer was discussed with regard to the property of the propagating active end.

KEY WORDS Anionic Polymerization / Methyl Methacrylate / Aprotic Dipolar Solvent / Hexamethylphosphoramide / Alkali Metal Alkoxide / Solvent Effect / Tacticity /
\end{abstract}

Hitherto it was known that alkali metal salts of primary alcohols cannot initiate the polymerization of methyl methacrylate (MMA) in ether. ${ }^{1}$ On the other hand, it was also wellknown that aprotic dipolar solvents such as hexamethylphosphoramide (HMPA) $^{2}$ and dimethylsulfoxide (DMSO) ${ }^{3}$ solvate cationic species strongly and hence promote the nucleophilic reactions. Several studies of the polymerization in such solvents have been reported, ${ }^{4-10}$ but there is very little information relating to the role of such solvents. In the previous paper, ${ }^{11,12}$ we reported that Grignard's reagents which did not polymerize styrene or $\alpha$-methylstyrene in toluene could polymerize these monomers in the presence of HMPA. It was concluded that such a drastic change is due to coordination of HMPA with the magnesium of Grignard's reagent.

In this paper, the polymerization of MMA by alkali metal alkoxides in the presence of aprotic dipolar solvents was investigated because it was expected that such solvents would increase the reactivity of the alkoxide.

\section{EXPERIMENTAL}

\section{Materials}

All the solvents used were purified by conventional methods: toluene, $p$-xylene, and tetrahydrofuran (THF) were distilled over metallic sodium under a nitrogen atmosphere. HMPA, DMSO, dimethylacetoamide (DMAc), dimethylformamide (DMF), $N, N, N^{\prime}, N^{\prime}$-tetramethylethylenediamine (TMEDA), diethylene glycol dimethyl ether (diglyme), and 1,2-dimethoxyethane (DME) were refluxed and distilled over calcium hydride either under a nitrogen atmosphere or in vacuo. MMA was purified by conventional methods, refluxed, and distilled over calcium hydride in vacuo just before use. Alcohols were refluxed and distilled over calcium hydride under a nitrogen atmosphere.

Sodium and potassium salts of the alcohols were prepared by the equimolar reactions of the corresponding alkali metals with the alcohols in toluene or in $p$-xylene. The alkoxide solution in HMPA was prepared from the corresponding $p$-xylene solution by removing this solvent under vacuum and adding HMPA to the dry alkoxide salt. Lithium alkoxide was prepared by the reaction of lithium metal with an excess of 
alcohol followed by removing the excess under vacuum. The concentration of the alkoxides was determined by acid-base titration.

\section{Polymerization Procedure}

The polymerization was carried out under a nitrogen atmosphere. In a $30-\mathrm{m} l$ polymerization tube equipped with a self-sealing rubber cap, the monomer and a solvent were charged and the mixture was brought to the polymerization temperature. The polymerization was initiated by introducing a toluene solution of a catalyst with a syringe through the rubber cap. After a given time the polymerization mixture was poured into methanol. The precipitated polymer was collected by filtration, washed with methanol, and dried in vacuo at $50^{\circ} \mathrm{C}$.

\section{Measurements}

Reduced viscosities were measured in a benzene solution at $25^{\circ} \mathrm{C}$. The NMR spectra of the polymer solution in nitromethane were measured at $120^{\circ} \mathrm{C}$ by means of a JNM C- $60 \mathrm{H}$ spectrometer. The degree of association of the alkoxides was measured by the cryoscopic method in $p$-xylene $\left(K_{\mathrm{f}}=4.3^{13}\right)$ and in HMPA $\left(K_{\mathrm{f}}=6.93^{14}\right)$ under a nitrogen atmosphere.

\section{RESULTS}

Effects of the Addition of Aprotic Dipolar Solvents

Figure 1 shows the results of the polymerization of MMA by sodium 2-methoxyethoxide in

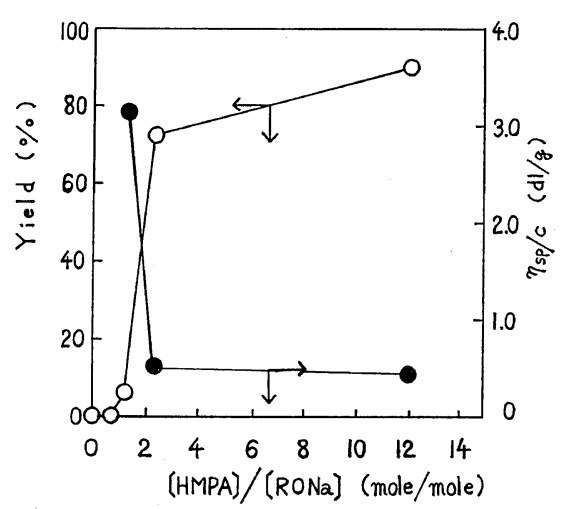

Figure 1. Polymerization of MMA with $\mathrm{CH}_{3}$ $\mathrm{OCH}_{2} \mathrm{CH}_{2} \mathrm{ONa}$ on addition of HMPA in toluene: $[\mathrm{M}]_{0}, 2.34 M ; \quad\left[\mathrm{CH}_{3} \mathrm{OCH}_{2} \mathrm{CH}_{2} \mathrm{ONa}\right], 2.41 \times 10^{-2} M$; temp, $0^{\circ} \mathrm{C}$; time, $23 \mathrm{hr} ; \eta_{\mathrm{sp}} / c$, benzene solution at $25^{\circ} \mathrm{C}, c=0.25 \mathrm{~g} / \mathrm{d} l$.

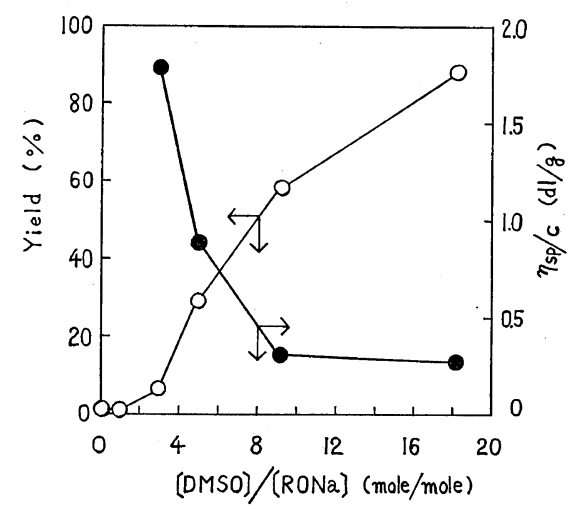

Figure 2. Polymerization of MMA with $\mathrm{CH}_{3^{-}}$ $\mathrm{OCH}_{2} \mathrm{CH}_{2} \mathrm{ONa}$ on addition of DMSO in toluene: $[\mathrm{M}]_{0}, 2.34 M ; \quad\left[\mathrm{CH}_{3} \mathrm{OCH}_{2} \mathrm{CH}_{2} \mathrm{ONa}\right], \quad 1.92 \times 10^{-2} M$; temp, $0^{\circ} \mathrm{C}$; time, $24 \mathrm{hr} ; \eta_{\mathrm{sp}} / c$, benzene solution at $25^{\circ} \mathrm{C}, c=0.25 \mathrm{~g} / \mathrm{d} l$.

the presence of HMPA. The polymerization did not occur with this alkoxide alone, while it proceeded easily on addition of HMPA. The yields of polymers increased with increasing molar ratio of HMPA/alkoxide. The molecular weights of polymers, on the contrary, decreased with an increase in HMPA concentration, and became approximately constant at higher HMPA concentration.

The results of the polymerization on addition of DMSO are shown in Figure 2. The behavior of the polymerization in the presence of DMSO was found to be similar to that in the case of HMPA. However, HMPA was slightly more effective as an additive for the polymerization than DMSO. The polymerization occurred also on addition of other solvents such as DMAc and DMF, while it did not on addition of THF, TMEDA, sulfolane, triphenylphosphine, or dipyridyl. These facts indicate that, as was expected, the aprotic dipolar solvent increased the reactivity of the alkoxide.

Effects of Solvent and the Structure of Catalyst

Table I shows the results of the polymerization initiated with various alkoxides in various solvents. Sodium $n$-butoxide could initiate the polymerization of MMA in HMPA, DMSO, DMAc, THF, and diglyme, but not in TMEDA, DME, or toluene. Lithium 2-methoxyethoxide could initiate the polymerization only in HMPA, DMSO, and DMAc, while the sodium salt could 
Table I. Polymerization of MMA by alkali metal alkoxides

(a) Effects of solvent ${ }^{a}$

\begin{tabular}{|c|c|c|c|}
\hline Initiator & Solvent & $\begin{array}{c}\text { Yield, } \\
\%\end{array}$ & $\begin{array}{c}\eta_{\mathrm{sp}} / C, \mathrm{~b} \\
\mathrm{~d} l / \mathrm{g}\end{array}$ \\
\hline \multirow[t]{8}{*}{$n$-BuONa } & HMPA & 60 & 0.30 \\
\hline & DMSO & 54 & 0.22 \\
\hline & DMAc & 11 & 0.13 \\
\hline & TMEDA & 0 & - \\
\hline & Diglyme & 5 & - \\
\hline & DME & 2 & - \\
\hline & THF & 11 & - \\
\hline & Toluene & 0 & - \\
\hline \multirow[t]{8}{*}{$\mathrm{CH}_{3} \mathrm{OCH}_{2} \mathrm{CH}_{2} \mathrm{OLi}$} & HMPA & 100 & 0.20 \\
\hline & DMSO & 90 & 0.14 \\
\hline & DMAc & 96 & 0.32 \\
\hline & TMEDA & 0 & - \\
\hline & Diglyme & 0 & - \\
\hline & DME & 0 & - \\
\hline & THF & 0 & - \\
\hline & Toluene & 0 & 一 \\
\hline \multirow[t]{8}{*}{$\mathrm{CH}_{3} \mathrm{OCH}_{2} \mathrm{CH}_{2} \mathrm{ONa}$} & HMPA & 100 & 0.24 \\
\hline & DMSO & 91 & 0.14 \\
\hline & DMAc & 84 & 0.22 \\
\hline & TMEDA & 90 & 0.31 \\
\hline & Diglyme & 61 & 0.16 \\
\hline & DME & 35 & 0.18 \\
\hline & THF & 38 & 0.33 \\
\hline & Toluene & 0 & - \\
\hline $\mathrm{CH}_{3} \mathrm{OCH}_{2} \mathrm{CH}_{2} \mathrm{OK}$ & Toluene & 93 & 0.57 \\
\hline
\end{tabular}

a $[\mathrm{M}] 0,2.34 M$; [Initiator], $2.2 \times 10^{-2} M$; solvent, 5 $\mathrm{ml}$; temp, $0^{\circ} \mathrm{C}\left(20^{\circ} \mathrm{C}\right.$ in the case of DMSO); time, $20 \mathrm{hr}$.

b Benzene solution at $25^{\circ} \mathrm{C}, C=0.25 \mathrm{~g} / \mathrm{d} l$.

(b) Effects of the structure of alkoxidea

\begin{tabular}{|c|c|c|c|c|c|c|c|}
\hline \multicolumn{2}{|c|}{ Initiator, $\mathrm{RCH}_{2} \mathrm{CH}_{2} \mathrm{OM}$} & \multirow{2}{*}{$\begin{array}{c}\text { Initiator } \\
\text { concn } \times 10^{2} \\
M\end{array}$} & \multirow{2}{*}{\multicolumn{2}{|c|}{$\begin{array}{c}\text { Donor solvent } \\
\text { [Donor]/[Initiator], } \\
\mathrm{mol} / \mathrm{mol}\end{array}$}} & \multirow{2}{*}{$\underset{\mathrm{hr}}{\mathrm{Time}}$} & \multirow{2}{*}{$\underset{\%}{\text { Yield, }}$} & \multirow{2}{*}{$\begin{array}{c}\eta_{\mathrm{sp} /} / C, \mathrm{~b} \\
\mathrm{~d} l / \mathrm{g}\end{array}$} \\
\hline $\mathbf{R}$ & $M$ & & & & & & \\
\hline$\left(\mathrm{CH}_{3}\right)_{2} \mathrm{~N}$ & $\mathrm{Na}$ & 1.94 & DMSO & 3.6 & 18 & 42 & 0.82 \\
\hline$\left(\mathrm{CH}_{3}\right)_{2} \mathrm{~N}$ & $\mathrm{Na}$ & 1.65 & HMPA & 2.0 & 12 & 92 & 0.37 \\
\hline $\mathrm{CH}_{3} \mathrm{O}$ & $\mathrm{Na}$ & 2.23 & DMSO & 3.2 & 18 & 13 & 1.40 \\
\hline $\mathrm{CH}_{3} \mathrm{O}$ & $\mathrm{Na}$ & 2.41 & HMPA & 2.4 & 23 & 74 & 0.50 \\
\hline $\mathrm{CH}_{3} \mathrm{CH}_{2}$ & $\mathrm{Na}$ & 2.20 & HMPA & 20 & 43 & 0 & - \\
\hline $\mathrm{CH}_{3} \mathrm{CH}_{2}$ & $\mathrm{Na}$ & 2.20 & HMPA & 185 & 20 & 60 & 0.30 \\
\hline $\mathrm{CH}_{3} \mathrm{O}$ & $\mathrm{K}$ & 0.77 & HMPA & 0.9 & 16 & 79 & 0.56 \\
\hline $\mathrm{CH}_{3} \mathrm{O}$ & $\mathrm{Na}$ & 2.41 & HMPA & 1.2 & 23 & 6 & 3.25 \\
\hline $\mathrm{CH}_{3} \mathrm{O}$ & $\mathrm{Li}$ & 2.42 & HMPA & 4.1 & 100 & 0 & - \\
\hline $\mathrm{CH}_{3} \mathrm{O}$ & $\mathrm{Li}$ & 2.42 & HMPA & 180 & 1 & 99 & 0.20 \\
\hline
\end{tabular}

a $[\mathrm{M}]_{0}, 2.34 M$; solvent, toluene; temp, $0^{\circ} \mathrm{C}$.

b Benzene solution at $25^{\circ} \mathrm{C}, C=0.25 \mathrm{~g} / \mathrm{d} l$. polymerize MMA in all the solvents except toluene. The potassium salt, moreover, could initiate the polymerization even in toluene. These results indicate that aprotic dipolar solvents such as HMPA, DMSO, and DMAc are most effective for the increasing the reactivity of the alkoxide.

The reactivity of the alkoxide was also found to be dependent on the structure of the alkoxide. In the case of the $n$-butoxide, the polymerization proceeded only in the presence of large amounts of the aprotic dipolar solvents, while the methoxy and the dimethylamino derivatives could polymerize MMA in the presence of small amounts of these solvents. In conclusion, the reactivities of the alkoxides as the initiator decreased in the order

\section{$\left(\mathrm{CH}_{3}\right)_{2} \mathrm{NCH}_{2} \mathrm{CH}_{2} \mathrm{O}^{-}>\mathrm{CH}_{3} \mathrm{OCH}_{2} \mathrm{CH}_{2} \mathrm{O}^{-}$ $\gg \mathrm{CH}_{3} \mathrm{CH}_{2} \mathrm{CH}_{2} \mathrm{CH}_{2} \mathrm{O}^{-}$}

Table I shows also that the reactivities of the catalysts concerning counter ions decreased in the order

$$
\mathrm{K}>\mathrm{Na}>\mathrm{Li}
$$

\section{Structure of Polymers}

The tacticity of poly(methyl methacrylate) obtained under various conditions was measured by NMR spectroscopy. ${ }^{15}$ The results are shown in Table II and Figure 3, which shows the relationship between the triad tacticity and Bovey's single-term parameter, $\sigma$. The syndiotacticity was found to increase with increasing 
Polymerization of Methyl Methacrylate by Alkoxide

Table II. The triad tacticity $(I, H$, and $S$ ) of poly(methyl methacrylate) obtained by the polymerization with alkali metal alkoxides ${ }^{a}$

\begin{tabular}{|c|c|c|c|c|c|c|}
\hline \multirow{2}{*}{$\begin{array}{l}\text { Number } \\
\text { in Figure } 3\end{array}$} & \multirow{2}{*}{$\begin{array}{c}\mathrm{M} \text { in initiator, } \\
\mathrm{CH}_{3} \mathrm{OCH}_{2} \mathrm{CH}_{2} \mathrm{OM}\end{array}$} & \multirow{2}{*}{\multicolumn{2}{|c|}{$\begin{array}{c}\text { Donor solvent } \\
\text { [Donor]/[Initiator], } \\
\mathrm{mol} / \mathrm{mol}\end{array}$}} & \multicolumn{3}{|c|}{ Tacticity, $\%$} \\
\hline & & & & $I$ & $H$ & $S$ \\
\hline 1 & $\mathrm{Li}$ & HMPA & 148 & 11 & 35 & 54 \\
\hline 2 & $\mathrm{Li}$ & HMPA & 74 & 10 & 38 & 52 \\
\hline 3 & $\mathrm{Na}$ & HMPA & 2.4 & 11 & 43 & 46 \\
\hline 4 & $\mathrm{Na}$ & HMPA & 11.8 & 6 & 40 & 54 \\
\hline 5 & $\mathrm{Na}$ & DMSO & 1.2 & 58 & 26 & 16 \\
\hline 6 & $\mathrm{Na}$ & DMSO & 2.4 & 37 & 34 & 29 \\
\hline 7 & $\mathrm{Na}$ & DMSO & 4.9 & 30 & 38 & 32 \\
\hline 8 & $\mathrm{Na}$ & DMSO & 9.1 & 12 & 47 & 42 \\
\hline 9 & $\mathrm{Na}$ & DMF & 4.1 & 79 & 12 & 9 \\
\hline 10 & $\mathrm{~K}$ & HMPA & 0.9 & 24 & 51 & 25 \\
\hline
\end{tabular}

a Polymerization conditions: $[\mathrm{M}]_{0}, 2.34 M$; [Initiator], 1.9-2.4 $\times 10^{-2} M$; solvent, toluene; temp, $0^{\circ} \mathrm{C}$; time, $16-24 \mathrm{hr}$.

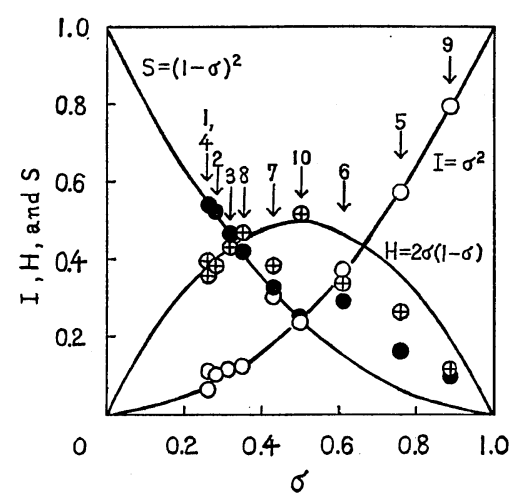

Figure 3. Tacticity of poly(methyl methacrylate) and Bovey's single-term parameter, $\sigma: \bigcirc, I ; \oplus, H$; ๑, $S$; numbers in the figure are defined in Table II.

molar ratio of donor-solvent/alkoxide, and to increase in the presence of the donor solvents in the following order: HMPA $>$ DMSO $>$ DMF. The triad tacticity of the polymers obtained on addition of small quantities of DMSO or DMF did not obey the statistics of Bovey's singleterm parameter, while that of the polymers obtained in the presence of a small and a large amounts of HMPA or a large amount of DMSO obeyed such statistics. This result indicates the absence of the penultimate effect in the latter case. Association of Alkali Metal Alkoxides

Table III shows the degree of association of alkali metal alkoxides in $p$-xylene and in HMPA. In the case of sodium 2-substituted ethoxides,
Table III. Association of alkali metal alkoxides in $p$-xylene and HMPA

\begin{tabular}{|c|c|c|c|c|}
\hline \multicolumn{2}{|c|}{$\begin{array}{c}\text { Alkoxide, } \\
\mathrm{RCH}_{2} \mathrm{CH}_{2} \mathrm{OM}\end{array}$} & \multirow{2}{*}{$\underset{M}{\operatorname{Concn}} \times 10$} & \multicolumn{2}{|c|}{$\begin{array}{c}\text { Degree } \\
\text {, of association in }\end{array}$} \\
\hline $\mathbf{R}$ & M & & $p$-xylene & HMPA \\
\hline $\mathrm{CH}_{3} \mathrm{O}$ & $\mathrm{Na}$ & 1.18 & $11 \pm 1$ & \\
\hline $\mathrm{CH}_{3} \mathrm{O}$ & $\mathrm{Na}$ & 1.20 & & $4 \pm 0.5$ \\
\hline $\mathrm{CH}_{3} \mathrm{O}$ & $\mathrm{Li}$ & 1.23 & $8.5 \pm 1$ & \\
\hline $\mathrm{CH}_{3} \mathrm{O}$ & $\mathrm{Li}$ & 1.20 & & $5 \pm 0.5$ \\
\hline$\left(\mathrm{CH}_{3}\right)_{2} \mathrm{~N}$ & $\mathrm{Na}$ & 1.23 & $9 \pm 1$ & \\
\hline$\left(\mathrm{CH}_{3}\right)_{2} \mathrm{~N}$ & $\mathrm{Na}$ & 1.16 & & $7 \pm 1$ \\
\hline$\left(\mathrm{CH}_{3}\right)_{2} \mathrm{~N}$ & $\mathrm{Li}$ & 1.20 & $2.5 \pm 0.5$ & \\
\hline $\mathrm{CH}_{3} \mathrm{CH}_{2}$ & $\mathrm{Na}^{\mathrm{a}}$ & 0.90 & & $2 \pm 0.5$ \\
\hline
\end{tabular}

a This salt was only slightly soluble in p-xylene.

the degree of association in $p$-xylene was about ten, while these alkoxides were present as less aggregated forms in HMPA. The degrees of association of $\mathrm{RCH}_{2} \mathrm{CH}_{2} \mathrm{ONa}$ in HMPA with three different $\mathrm{R}$ were found to decrease in the order: $\left(\mathrm{CH}_{3}\right)_{2} \mathrm{~N}->\mathrm{CH}_{3} \mathrm{O}->\mathrm{CH}_{3} \mathrm{CH}_{2}-$ The variation in the degree of association with counter ions was small in the case of the methoxy derivative, but was considerably larger in the dimethylamino derivative. The degree of association of the potassium salts could not be measured because the salts were only slightly soluble in $p$-xylene and HMPA.

\section{DISCUSSION}

It was confirmed that the alkali metal alkoxides 
can initiate the polymerization of MMA in the presence of the aprotic dipolar solvents. The alkoxides are known to associate in ether ${ }^{16}$ and even in HMPA. ${ }^{5,17}$ The result obtained in this study also supports such a fact. It could be assumed, therefore, that the alkoxides are also present as aggregated forms in the polymerization systems, though the polymerization was done at lower concentration of the alkoxide than that in the measurement of the degree of association. The fact that the alkoxide associates appreciably even in HMPA suggests that the degree of association of the alkoxide must scarcely decrease in a mixture of solvents of toluene and a small amount of HMPA. Sodium dimethylaminoethoxide, which is the most aggregated species in HMPA, was most effective as the initiator, while the $n$-butoxide, the less aggregated species, was less effective. Moreover, the lithium salts was less effective than the sodium salts, though the degrees of association of both salts did not differ too greatly. These findings suggest that the reactivity of the alkoxide, at least in a mixture of solvents of toluene and a small amount of a donor such as HMPA, cannot be explained only in terms of the extent of association of the alkoxide.

In the case of the reactions of alkoxides with ethylene oxide, ${ }^{5,18}$ vinylidene chloride, ${ }^{19}$ or $\mathrm{MMA},{ }^{20}$ the active species are usually considered to be monomeric species (ion pair and/or free ion), which coexist at equilibrium with aggregated species

$$
\begin{aligned}
& \frac{1}{n}\left(\mathrm{RO}^{-} \mathrm{M}^{+}\right)_{n} \rightleftarrows \mathrm{RO}^{-} \mathrm{M}^{+} \rightleftarrows \mathrm{RO}^{-}+\mathrm{M}^{+} \\
& \text {(aggregates) (ion pair) (free ion) }
\end{aligned}
$$

In this study, alkali metal salts of 2-substituted ethanols such as 2-methoxyethanol and 2-dimethylaminoethanol were used as the initiator. In such a case, the ion pairs seem to have five-membered rings which could be formed by the coordination of the hetero atoms in the substituents with the counter ions, as shown in Figure $4 .^{19}$ Such alkoxides with sodium or lithium counter ions, however, were not effective as the initiator in the absence of the donor, though the methanol-soluble oligomer might be formed. This fact could be explained on the assumption that the oxygen-metal bonds of

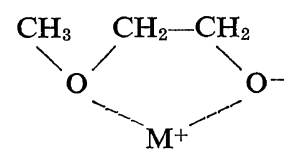

(Ia)<smiles></smiles>

(Ib)
Figure 4. Intramolecular association of alkoxides: $\mathrm{M}$ is $\mathrm{Li}, \mathrm{Na}$, or $\mathrm{K}$.

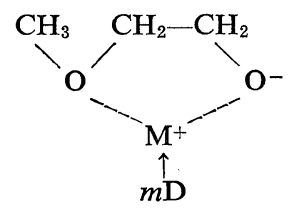

(IIa)<smiles></smiles>

(IIb)
Figure 5. Coordination of donor with counter ion: $\mathrm{M}, \mathrm{Li}$ or $\mathrm{Na}$; $\mathrm{D}$, donor; $m$, number of donor moleculs coordinated to a counter ion.

these alkoxides are not polarized enongh to react with the MMA. In the presence of the donor, moreover, such species could be assumed to change to more polar species which can react with MMA. The free ions and the activated ion pairs ${ }^{20}$ such as Formula IIa and IIb seem to correspond to such polar species. The electric conductivity of sodium 2-methoxyethoxide, however, was too small to be measured in a mixture of toluene and a small amount of HMPA. This fact suggests that the free ion was scarcely present in such a mixture of solvents. On the other hand, the activated ion pair, which is formed by the coordination of the donor to the counter ion, may be regarded as an agentseparated ion-pair. ${ }^{21}$ The oxygen-metal bonds of species IIa and IIb must be more polar than those of species $\mathbf{I a}$ and $\mathbf{I b}$, respectively, which are present in the absence of the donor, and hence species IIa and IIb could initiate the polymerization of MMA.

The explanation for the observed order in the reactivities of the initiators concerning 2-substituents is given below. The nitrogen of the dimethylamino group is considered to interact with alkali metal ions more strongly than the oxygen of the methoxy group. Actually the electronic spectra ${ }^{22}$ of 9-substituted fluorenyl salts as Formula III showed that the relative amounts of the contact ion-pairs in THF decreased with $\mathrm{R}$ in the order: $\left(\mathrm{CH}_{3}\right)_{2} \mathrm{~N}->\mathrm{CH}_{3} \mathrm{O}-\gg$ $\mathrm{CH}_{3} \mathrm{CH}_{2}$-. 


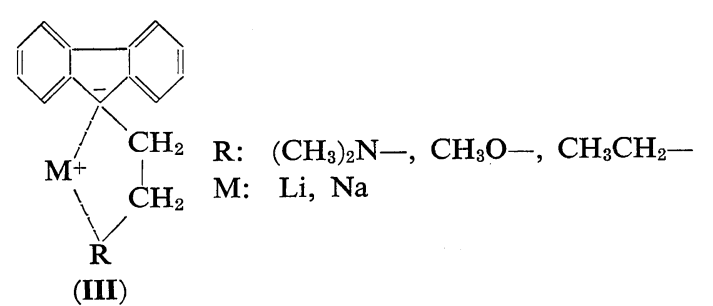

This fact suggests that the interaction of the substituents with the alkali cations decreases in such an order. The oxygen-metal bond of the dimethylamino derivative (species IIb), therefore, seems to be more polarized than that of the methoxy derivative (species IIa). Such a polarization of the oxygen-metal bond cannot be expected in the case of the $n$-butoxide. In conclusion, a strengthening of the coordination of the hetero atom in the substituent is considered to result in an increasing of the reactivity of the alkoxide.

The reactivities of the alkoxides concerning counter ions were found to increase with decreasing ionization potentials of the corresponding alkali metals. The oxygen-metal bond of the potassium alkoxide is more polar than that of the sodium salt, ${ }^{23}$ and hence the potassium salt seems to be effective as the initiator even in the absence of the donor solvent. A similar explanation must also be reasonable in a comparison of the reactivities of the sodium and the lithium salts.

The aprotic dipolar solvents were found to increase markedly the reactivity of the alkali metal alkoxide. Such a solvent effect could be explained in terms of the donor charactor and the dielectric constant of the solvent, as given below. Recently Gutmann ${ }^{24}$ proposed the donor number or donicity $(D n)$ as a measure of the donor property of the solvent. However, it has not been clear whether or not the donicity is a valuable guide in the explanation for the interaction of "hard" ions ${ }^{25}$ with the solvents. It has been reported by Popov, et al. ${ }^{26}$ that the plot of the ${ }^{23} \mathrm{Na}$ chemical shifts for the sodium tetraphenylborate solutions vs. Gutmann's donor numbers is linear. The donor number, therefore, seems to be effective in accounting for the interaction of the hard ion such as an alkali metal ion with the donor solvent. The solvents such as HMPA, DMSO, and DMAc having high donor numbers $(D n=38.8,29.8$, and 27.8 , respectively ${ }^{24}$ ) could coordinate highly with the counter cation of the alkoxide and thereby increase the reactivity of the alkoxide as previously described. Though such three solvents have also high dielectric constants $(\varepsilon=$ $30.0,45.0$, and 28.9 at $25^{\circ} \mathrm{C}$, respectively ${ }^{24}$ ), it seems reasonable to assume that there is little difference in the dielectric constants between toluene, a mixture of solvents of toluene and a small amount of such a donor. Moreover, the fact that a small quantity of the donor solvent affected the reactivity of the alkoxide suggests that the coordination of the donor to the alkali cation plays a principal role in increasing the reactivity at least in the system containing a small amount of the donor. It could therefore be accounted for by the difference in the donicities that HMPA was slightly more effective as an additive than DMSO.

Such a coordination must also affect the propagation reaction in addition to the initiation. Actually the syndiotacticity of the polymer obtained on addition of the donor solvent increased with an increase in the concentration of the donor, and the penultimate effect disappeared at the same time. This fact suggests that propagation by a free ion or a solvent-separated ion pair, ${ }^{27}$ which are formed by the interaction of a propagating ion-pair with the donor becomes predominant as the concentration of the donor increases. The effect of the donor solvents on the syndiotacticity of the polymers could also be explained in terms of the order in the donicities of the solvents, that is, HMPA $>$ DMSO $>$ DMF. $^{24}$ The effect of the donor on the molecular weight of the polymer could not be discussed, because the effect of the donor on the rates of initiation, propagation, or termination was not investigated in this study. The results as showed in Figure 1 and 2 , however, could be explained by assuming that the initiator efficiency increased with an increase of the concentration of the donor, from analogy with the results of the polymerization of styrene ${ }^{11}$ and $\alpha$-methylstyrene ${ }^{12}$ with the organomagnesium compounds/HMPA system.

The polymerization with sodium 2-methoxyethoxide proceeded moderately in solvents such 
as TMEDA, diglyme, DME, and THF, while these solvents were not as effective as the additive. The donor numbers of these solvents except THF $(D n=20.0)$ are not reported by Gutmann, ${ }^{24}$ but it is reported by Agami and Caillot $^{28}$ that the donor charactors (for chloroform or phenylacetylene) of DME and diglyme are almost equal to the donor charactor of THF, and that these ethers are very inferior to HMPA or DMSO as the donor. However, it can not be understood that TMEDA was not effective as the additive, because TMEDA and DMSO are reported to interact with chloroform to a similar extent ${ }^{28}$ and the donor number of TMEDA is considered to be similar to that of HMPA $(D n=\sim 55$ in the case of primary amines ${ }^{29}$ ). In the presence of a large amount of the donor solvent, the dielectric charactor of the solvent is also a significant factor because the dissociation of ion pairs into free ions must proceed easily with an increase in the dielectric constant of the reaction medium. ${ }^{24}$ The effectiveness of the ethers as the media seems to be due to the moderate dielectric constants $\left(\varepsilon \sim 6^{30}\right)$ in addition to the donor charactors of the ethers.

\section{REFERENCES}

1. N.S. Wooding and W.C.E. Higginson, $J$. Chem. Soc., 774 (1952).

2. H. Normant, Angew. Chem., 79, 1029 (1967).

3. D. Martin, A. Weise, and H. J. Niclas, ibid., 79, 340 (1967).

4. C. E. H. Bawn, A. Ledwith, and N. R. McFarlane, Polymer, 10, 653 (1969).

5. J. E. Figueruelo and D. J. Worsfold, Eur. Polym. J., 4, 439 (1968).

6. G. D. Cooper, J. Polym. Sci., Part A-1, 4, 603 (1966).

7. H. L. Needles, ibid. Part A-1, 7, 1437 (1969).

8. B. Erussalimsky and I. Krassnoseslskaya, Makromol. Chem., 123, 80 (1969).
9. A. Priola and L. Trossarelli, ibid., 139, 281 (1970).

10. K. Yamaguchi and Y. Minoura, J. Polym. Sci., Part A-1, 10, 63 (1972).

11. M. Tomoi and H. Kakiuchi, Kogyo Kagaku Zasshi (J. Chem. Soc. Japan, Ind. Chem. Sect.), 73, 2367 (1970).

12. M. Tomoi and H. Kakiuchi, Polymer J., 5, 195 (1973).

13. J. A. Riddick and W. B. Bunger, "Organic Solvents," 3 rd ed, Wiley-Interscience, New York, N.Y., 1970, p 114.

14. J. Ducom, C. R. Acad. Sci., C264, 722 (1967).

15. F. A. Bovey and G. V. D. Tiers, J. Polym. Sci., 44, 173 (1960).

16. D. G. Hill, J. Burkus, S. M. Luck, and C. R. Hauser, J. Amer. Chem. Soc., 81, 2787 (1959).

17. J. E. Figuerelo and A. Bello, J. Macromol. Sci.-Chem., A3, 311 (1969).

18. G. Gee, W. C. E. Higginson, P. Levesley, and K. J. Taylor, J. Chem. Soc., 1338 (1959).

19. W. C. Kuryla, J. Org. Chem., 30, 3926 (1965).

20. J. Trekoval, J. Polym. Sci., Part A-1, 9, 2575 (1971).

21. M. Shinohara, J. Smid, and M. Szwarc, J. Amer. Chem. Soc., 90, 2175 (1968).

22. M. Tomoi and H. Kakiuchi, unpublished results.

23. T. Yamamoto, Kagaku To Kogyo, 23, 1004 (1970).

24. V. Gutmann, Angew. Chem., 82, 858 (1970).

25. R. G. Pearson, J. Amer. Chem. Soc., 85, 3533 (1963).

26. R. H. Erlich and A. I. Popov, ibid., 93, 5630 (1971).

27. Y. Inoue, R. Chûjô, and A. Nishioka, Polymer J., 2, 13 (1971).

28. C. Agami and M. Caillot, Bull. Soc. Chim. France, 1990 (1969).

29. M. Herlem and A. I. Popov, J. Amer. Chem. Soc., 94, 1431 (1972).

30. J. L. Down, J. Lewis, B. Moore, and G. Wilkinson, J. Chem. Soc., 3767 (1959). 